\title{
Total Surface Area in Indoor Environments
}

\section{Archit Manuja}

Thesis submitted to the faculty of the Virginia Polytechnic Institute and State University in partial fulfillment of the requirements for the degree of

\author{
Master of Science \\ In \\ Environmental Engineering \\ Linsey C. Marr, Chair \\ John C. Little \\ Gabriel Isaacman-VanWertz
}

April $17^{\text {th }}, 2018$

Blacksburg, VA

Keywords: surface, area, volume, built environment, indoor air, deposition

Copyright (C) 2018, Archit Manuja 


\title{
Total Surface Area in Indoor Environments
}

\section{Archit Manuja}

\begin{abstract}
Certain processes in indoor air, such as deposition, partitioning, and heterogeneous reactions, involve interactions with surfaces. To accurately describe the surface-area-to-volume ratio in a room, we have characterized the surface area, volume, shape, and material of objects in five bedrooms, four kitchens, and three offices. Averaged over all types of rooms, the ratio of surface area with contents to that without contents was $1.7 \pm 0.2$ (mean \pm standard error), and the ratio of volume of freely moving air to volume of the entire space was $0.89 \pm 0.05$. Ignoring contents, the surface-area-to-volume ratio was $1.9 \pm 0.3 \mathrm{~m}^{-1}$; accounting for contents, the ratio was $3.7 \pm 1.2$ $\mathrm{m}^{-1}$. Ratios were not significantly different between room types and were comparable to those measured for 33 rooms in a similar study. Due to substantial differences in the design and contents of kitchens, their ratios had the highest variability among the three room types. On average, the contents of bedrooms, kitchens, and offices increase their surface area by $70 \%$ and decrease their volume of freely moving air by $11 \%$ compared to an empty room. The most common shape of objects in a room was a flat plate, while each room also had many irregularlyshaped objects. Paint and wood were the two most common materials in each room, although the distribution of materials varied by room type. The results of this study can be used to improve understanding of the behavior of gases and particles in indoor environments.
\end{abstract}




\section{Total Surface Area in Indoor Environments}

\section{Archit Manuja}

\section{GENERAL AUDIENCE ABSTRACT}

Since humans spend over $90 \%$ of their time indoors on average, understanding indoor air quality is essential for characterizing the relationship between health and the environment. Air pollutants can interact with surfaces in the indoor environment, not just surfaces of the walls, ceiling, and floor, but also of objects in the room. Researchers often combine information about the surface area and volume of a room into a single number, the surface-area-to-volume ratio. Many previous studies have estimated the ratio for an empty room, ignoring furniture, appliances, and other contents. We have characterized the surface area, volume, shape, and material of objects in five bedrooms, four kitchens, and three offices. Averaged over all types of rooms, the ratio of surface area with contents to that without contents was $1.7 \pm 0.2$ (mean \pm standard error), and the ratio of volume of freely moving air (i.e., volume of the empty room minus the volume of all contents) to that of the entire space was $0.89 \pm 0.05$. On average, the contents increased the room's surface area by $70 \%$ beyond that of the walls, floor, and ceiling alone, and decreased the volume of freely moving air by $11 \%$ compared to an empty room. Ignoring contents, the surface-area-to-volume ratio was $1.9 \pm 0.3 \mathrm{~m}^{-1}$, whereas accounting for contents, the ratio was nearly double, $3.7 \pm 1.2 \mathrm{~m}^{-1}$. The most common shape of objects in a room was a flat plate, while each room also had many irregularly-shaped objects. Paint and wood were the two most common materials in each room, although the distribution of materials varied by room type. These results can be used for developing realistic model simulations of air flow indoors, updating previously published models, or improving predictions of losses and gains of pollutants in indoor air. 


\section{Table of Contents}

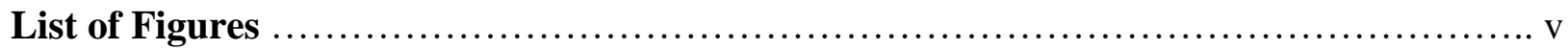

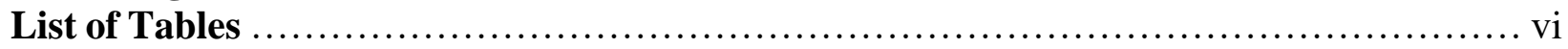

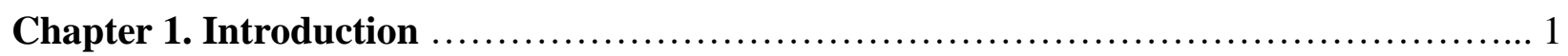

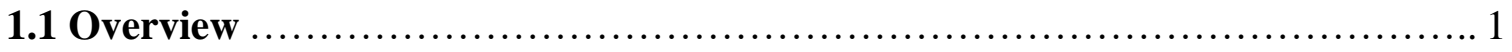

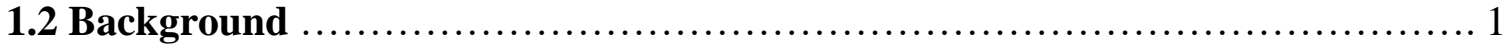

1.2.1 Modeling Indoor Environments ................................ 1

1.2.1.1 Particle Deposition ........................................................ 2

1.2.1.2 Gas Deposition ....................................... 3

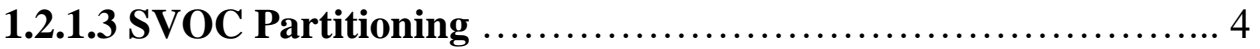

1.2.1.4 Modelling Air Flow ..................................... 5

1.2.2 Importance of Surface-Area-to-Volume Ratios ......................6 6

1.3 Review of $S / V$ Ratios in the Literature ..................................... 6

1.3.1 Overview ......................................................... 6

1.3.2 Mueller et al. ................................................. 7

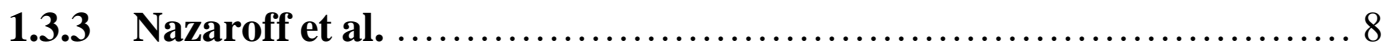

1.3.4 Hodgson et al. .................................................. 9

1.3.5 Review of Other Environmental Indoor Modeling Publications ........ 9

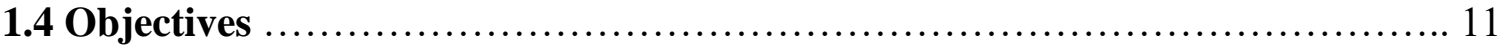

1.5 References ............................................................ 11

Chapter 2. Total Surface Area in Indoor Environments .............................. 15

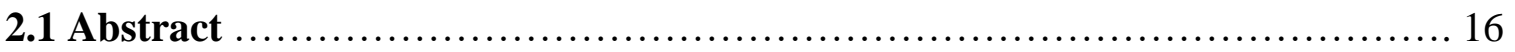

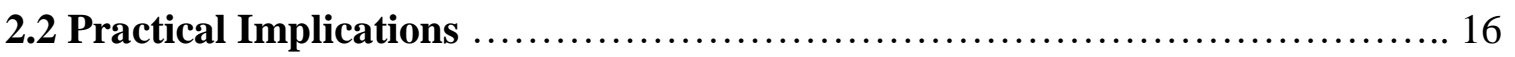

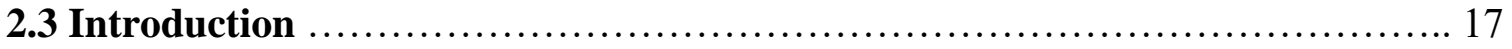

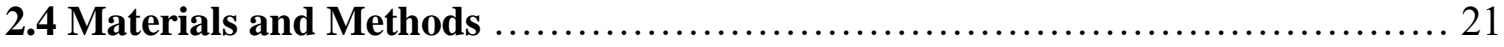

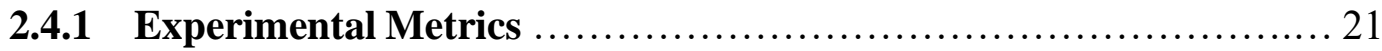

2.4.2 Indoor Environments .......................................... 22

2.4.3 Measurement Techniques ...................................... 22

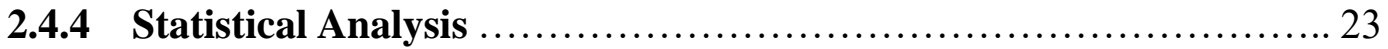

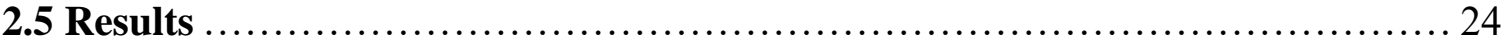

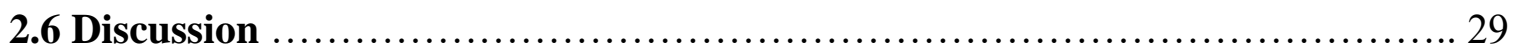

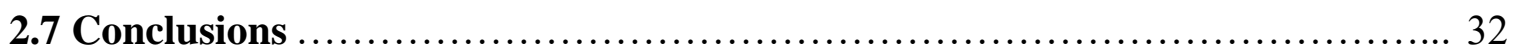

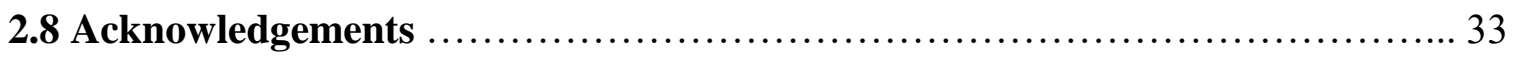

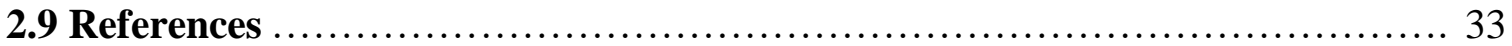

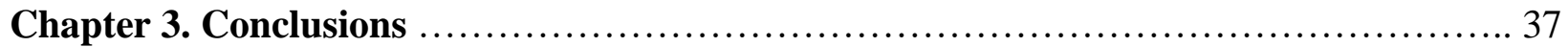

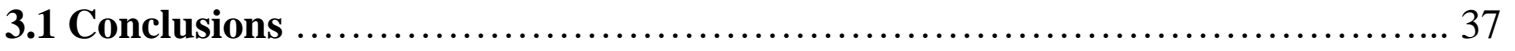

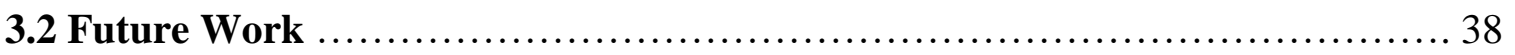




\section{List of Figures}

Figure 2.1. Ratios (mean \pm standard deviation) of surface area with contents to surface area without contents $\left(S^{*} / S\right)$; volume with contents to volume without contents $\left(V^{*} / V\right)$; surface area to volume without contents $(S / V)$; surface are area volume with contents $\left(S^{*} / V^{*}\right)$ for each type of room, and overall ratios (mean \pm standard error) for all three room types combined........................... 27

Figure 2.2. Surface area by shape of all contents in each room........................... 28

Figure 2.3. Surface area by material of all contents in each room.......................... 29

Figure 2.4. Number of contents, including floor, ceiling, and each wall, required to achieve a certain amount of the total exposed surface area. Red is bedrooms, blue is kitchens, and green is offices. The dashed line indicates $90 \%$ of the total surface area.......................... 32 


\section{List of Tables}

Table 1.1 Surface-area-to-volume ratios used in previous experimental and conceptual indoor models.................................................................... 10

Table 2.1. Surface-to-volume ratios of indoor environments in previous studies and this study, grouped roughly by type of room and whether contents are included...................... 20

Table 2.2. Dimensions, surface area without $(\mathrm{S})$ and with $\left(\mathrm{S}^{*}\right)$ contents, volume without $(\mathrm{V})$ and with $\left(\mathrm{V}^{*}\right)$ contents, and ratios for bedrooms, kitchens, and offices....................... 25 


\section{Chapter 1. Introduction}

\subsection{Overview}

The purpose of this thesis research is to support the development of accurate models of contaminant transport indoors by characterizing the total exposed surface area in different types of rooms, including their contents, which are often overlooked in studies of the indoor environment. The thesis is divided into three chapters. Chapter 1 provides background on modelling different indoor environments, as well as the role of surface area for developing such models. This chapter also includes a detailed literature review showcasing the variability in surface-area-to-volume ratios used in previous studies. Chapter 2 is a manuscript describing measurements of total surface area in three different types of rooms: bedrooms, kitchens, and offices. In addition to documenting the surface area of rooms and their contents, this section also describes the objects present in each type of room in terms of their shape and material. Chapter 3 summarizes the conclusions, while simultaneously discussing potential future research to improve modelling of indoor environments. This study fills a large gap in the literature, and results can be used widely for understanding the behavior of gases and particles in buildings.

\subsection{Background}

\subsubsection{Modelling Indoor Environments}

Since humans spend over $90 \%$ of their time indoors, on average ${ }^{1}$, understanding indoor air quality is essential for characterizing the relationship between health and the environment. The ability to predict exposure to various indoor pollutants, and their short-term and long-term effects, is important in determining solutions to minimize or mitigate any potential harmful consequences. Conceptual and numerical models are an important tool for understanding the transport and 
chemical transformations of gases and particles indoors. Such models, including mass-balance equations, can be used to predict the concentration, emission strength, and/or fate of indoor pollutants ${ }^{2}$.

Among the most basic inputs to such models are the surface area and volume of the room, often combined as the surface-area-to-volume ratio. Most applications of indoor air models assume values for a "typical" room or building and do not account for the contents of the room ${ }^{6,20,24,27}$. However, the room's contents can be important for gases and particles that interact with surfaces and should not be overlooked. The following sections illustrate the relevance of the surface-areato-volume ratio.

\subsubsection{Particle Deposition}

In addition to its health effects, airborne particulate matter (PM) can also cause chemical deterioration of materials ${ }^{3}$ and can even damage electrical equipment ${ }^{4}$. Particles found indoors can be transported from outdoors and can also be produced indoors, such as through cooking, smoking, or shedding of pet dander ${ }^{5}$. PM can be transported indoors through various ventilation systems, including heating and air conditioning systems, as well as doors, windows, cracks, and other openings ${ }^{6}$. Various studies have measured indoor PM concentrations and have derived penetration factors ${ }^{6}$, aerosol deposition rates, and indoor-outdoor concentration ratios ${ }^{7}$. Other studies have quantified the effect of an ion generator on PM concentration in a residential room ${ }^{8}$ and determined the effects of room furnishings and air speed on PM deposition rates ${ }^{5}$. In all these cases, deposition of airborne particles onto surfaces aids in removing these particles from the air $^{9}$, and improved characterization of these surfaces indoors will enable more accurate prediction of deposition. 
A mass-balance equation for particles in a well-mixed room is shown in (1). It accounts for particles entering and leaving the room via air flow into and out of the room, emissions, loss by reaction, and loss by deposition. Variables include the concentration of particles in the outdoor air flowing into the room $\left(\mathrm{C}_{\text {outdoors }}\right)$, concentration of particles in the indoor air flowing out of the room $\left(\mathrm{C}_{\text {indoors }}\right)$, flow rate of the air $(\mathrm{Q})$, emission rate of particles being generated indoors $(\mathrm{E})$, first-order reaction rate coefficient of particles indoors $(\mathrm{k})$, deposition velocity of the particles $\left(\mathrm{v}_{\mathrm{d}}\right)$, and surface area of the room (A).

$$
\frac{d\left(C_{\text {indoors }} V\right)}{d t}=Q C_{\text {outdoors }}-Q C_{\text {indoors }}+E-k C_{\text {indoors }} V-v_{d} A C_{\text {indoors }}
$$

The volume of the room is usually constant, leading to (2), where the surface-area-to-volume ratio (A/V) now appears in the last term.

$$
\frac{d\left(C_{\text {indoors }}\right)}{d t}=\frac{Q C_{\text {outdoors }}}{V}-\frac{Q C_{\text {indoors }}}{V}+\frac{E}{V}-k C_{\text {indoors }}-v_{d} \frac{A}{V} C_{\text {indoors }}
$$

The total loss of a pollutant is modeled as the product of the deposition velocity and the surfacearea-to-volume ratio ${ }^{3}$, and (2) applies to both particles and gases. The deposition velocity can vary significantly depending on the chemical properties of the species, particle size, density, and shape,

as well as the nature of the surface ${ }^{10}$. The total concentration of the particles present in the system can also significantly affect the total depositional loss.

\subsubsection{Gas Deposition}

While all gases can deposit to surfaces, those with the highest deposition velocities include ozone, nitric acid, formaldehyde, and hydrogen peroxide. Of these, the most commonly studied gas indoors is ozone. Researchers have assessed ozone decay rates within residences ${ }^{11}$, developed methods for removal of ozone ${ }^{12}$, measured the first-order decomposition of ozone ${ }^{13}$, and quantified 
ozone-induced secondary emissions of aldehydes on indoor surfaces ${ }^{14}$. Because ozone has a high deposition velocity, such research mostly accounts for uptake of ozone on surfaces.

Deposition of ozone indoors depends on the surfaces present in the room and the surface-area-tovolume ratio. For particles, deposition is simply a physical process, whereas for gases, chemical interactions between the gas of interest and the surface are an important determinant of the deposition velocity. The simple mass-balance model shown in (2) also applies to gases. For gases, the deposition velocity depends on solubility, chemical reactivity, as well as the type of surface ${ }^{10}$. These factors mostly depend on the materials present on the surface available for absorption or adsorption of the gases. Therefore, in addition to the size and shape of the contents in a room, the type of material is also important for developing a complete understanding of the decay rates of ozone and other gases indoors.

\subsubsection{SVOC Partitioning}

Semi-volatile organic compounds (SVOCs) are those whose vapor pressure means that they are present in at least two phases at ambient conditions, typically the gas phase and the condensed phase, where they may be associated with settled dust, airborne PM, or other surfaces ${ }^{4}$. Secondary pollutants can build up within an indoor environment through chemical reactions, direct release, or re-emission of SVOCs adsorbed to surfaces ${ }^{15}$. Many experimental studies have been conducted to understand the behavior of SVOCs indoors, their partitioning into different compartments, as well as their decay and re-emission rates. Weschler and Nazaroff ${ }^{16,17}$ developed ratios of SVOCs present simultaneously in the settled dust phase and in the gas phase, in indoor environments.

Similar to the experiments and models for particle deposition, surface-area-to-volume ratios are a necessary metric for understanding the SVOC decay and re-emission rates. These ratios can assist 
in predicting the total concentration of SVOCs in each phase, and the size and material of the contents present within each room should not be overlooked.

\subsubsection{Modelling Air Flow}

Air flow dynamics models, which represent the movement of air through mathematical equations, can be used for understanding the effectiveness of ventilation and heating systems within a building ${ }^{18}$, the effects of generation and/or decay of indoor pollutants, and the relationship between indoor and outdoor air quality. Air flow through a building can affect thermal comfort, effectiveness and efficiency of energy distribution, and impact of the ventilation systems ${ }^{18}$. A standard k- $\varepsilon$ model, which requires solving two differential equations to compute mean-flow quantities, can be used as a numerical model for simulating airflow through a room; however, these models have a high computational $\cos ^{19}$. Simpler computational fluid dynamics models, such as zero-equation turbulence models that do not require solving any additional differential equations, can be used, instead, for developing easily understood, and easily computed, models for understanding air flow indoors. These simpler models, however, still require the room geometry, including the dimensions, contents present, and all the inlet and outlet openings within the room ${ }^{19}$. Realistic model simulations of air flow indoors require accounting for the size, shape, and orientation of the contents of a room, along with an accurate surface-area-to-volume ratio.

In order to better understand exposure of these pollutants on an individual level, Hayes ${ }^{20}$ developed a personal air quality model (PAQM) for ozone and PM. PAQM accounts for various factors, including the segment of the population, amount of time spent indoors, indoor-outdoor concentration ratios, individual hourly activity patterns, and physical exercise level to predict the indoor air quality and total exposure. PAQM assumes a surface-area-to-volume ratio for different microenvironments. According to this model, the surface area is defined as the bottom horizontal 
area available for settling ${ }^{20}$ and is represented as the inverse of the ceiling height for a rectangular room since $\mathrm{S}$ is length times width $(\mathrm{L} \times \mathrm{W})$ and $\mathrm{V}$ is $(\mathrm{L} \times \mathrm{W} \times \mathrm{H})$. The exact values of $S / V$ used in Hayes' PAQM model are shown in Table 1.1. However, the actual surface area available for deposition of gases should also include any objects present in the room.

\subsubsection{Importance of Surface-Area-to-Volume Ratios}

Over their lifetime, humans spend a majority of their time indoors, living in their homes to working in offices or schools and visiting malls or restaurants. All these enclosed environments have different contents. We define the external surface area of a room excluding its contents as $S$ (i.e., walls, floor, and ceiling only), the surface area with contents as $S^{*}$, total nominal volume of the room as $V$, equal to length $(\mathrm{L}) \times$ width $(W) \times$ height $(H)$, and the volume of freely moving air in the room as $V^{*}$. The ratio $S^{*} / S$ is 1 if the room is empty and $S^{*}$ equals $S$, and likewise for $V^{*}$ and $V$. If the contents of the room have the same amount of surface area as the walls, floor, and ceiling, then $S * / S$ equals 2 . This is an important parameter to understand the movement of air through a room, as well as to understand the behavior of different pollutants in an indoor setting. In addition to $S * / S$, the two surface-area-to-volume ratios, without contents $(S / V)$ and with contents $\left(S^{*} / V^{*}\right)$, are also important for describing air flow, emission rates, and decay rates. These metrics are essential for visualizing, developing, and simulating realistic models of indoor rooms. In addition, these metrics can be used for designing indoor settings to optimize pollutant uptake in certain regions of a building and other design projects.

\subsection{Review of $S / V$ Ratios in the Literature}

\subsubsection{Overview}


Although many studies have modeled indoor environments, very few have accounted for the contents of a room. Most have used a "typical" value of $S / V$. Mueller et al. measured $S^{*} / V^{13}$ and Nazaroff et al. assumed a value of $S^{*} / V^{3}$, and these are frequently cited by other researchers who are modeling indoor environments. The two studies, described in further detail below, used appropriate and realistic surface-area-to-volume ratios for bedrooms and/or offices. The most comprehensive study of total surface area in rooms appears in a report by Hodgson et al. ${ }^{21}$ measuring $S * / V^{*}$ of 33 rooms, however this study has not been widely used by other researchers. Most other studies described either larger indoor environments, such as entire houses, or relatively smaller models, such as lab chambers. Table 1.1 summarizes all studies using $S / V$ or $S * / V$ values for indoor environments.

\subsubsection{Mueller et al.}

Mueller et al. ${ }^{13}$ focused on measuring the deposition rates of ozone in four indoor environments: aluminum odor test facility, metal test rooms, offices, and homes. The research objective was to evaluate ozone decomposition in indoor air in different environments in order to reliably predict the concentration of ozone for residential buildings or offices.

$S / V$ for the aluminum odor test facility was $5.3 \mathrm{~m}^{-1}$. We assume that this chamber did not have any contents and essentially acted as a closed, empty box. There were two metal test rooms: an aluminum test room and a stainless test room. The stainless test room was slightly bigger than the aluminum test room, and had a $S / V$ value of $2.7 \mathrm{~m}^{-1}$, while $S / V$ for the aluminum test room was 3.3 $\mathrm{m}^{-1}$. In the office, a $S * / V$ of $2.8 \mathrm{~m}^{-1}$ was calculated. Mueller wrote "this value was calculated by considering each piece of furniture as a rectangular parallelepiped." Using the same process for the bedroom in the home environment led to a $S * / V$ of $3.3 \mathrm{~m}^{-1}$. The $S * / V$ values obtained for the 
office and the home appear to be reasonable and have often been used by other researchers for their conceptual models.

Mueller concluded that one of the factors that could significantly influence the ozone decomposition rates is the effective surface area available for decomposition. He reiterated that the room volume, and the exposed surface area of the contents present in the room, are important for determining the travel path for air, and the surfaces particles could stick to, or settle on.

\subsubsection{Nazaroff et al.}

Nazaroff has developed various theoretical mathematical models to understand the behavior of pollutants suspended in air. His work ranges from conceptual models for decomposition of particles $^{22}$ to critiquing the use of deposition velocities in such models ${ }^{3}$, as well as understanding SVOC partitioning indoors ${ }^{16}$. To determine the rate of change of pollutant concentration, he used $S / V$ as one parameter ${ }^{22}$. In a critique of the use of particle deposition, he stated that the loss rate of pollutants from the air is the product of the surface-area-to-volume ratio and the deposition velocity. He listed various limitations regarding the use of deposition velocity for modelling indoor air quality, including assuming uniform mixing indoors and representing surface-pollutant reactions as first-order loss. In addition, he discussed the strengths and weaknesses of the relationship between deposition velocity and total loss of pollutants on surfaces. To calculate

pollutant loss rates, he assumed a "typical" $\mathrm{S} / V$ value of $2.8 \mathrm{~m}^{-1}$ along with previously published deposition velocities. Although the paper refers to the surface-area-to-volume ratio with contents, there is no explanation or justification for how this value was determined. 


\subsubsection{Hodgson et al.}

The most comprehensive study of total surface area in rooms appears in a report by Hodgson et al. ${ }^{21}$ They systematically measured all objects larger than $300 \mathrm{~cm}^{2}$ (about the surface area of a soda can) in 33 rooms in nine residences, encompassing 12 bedrooms that also functioned as offices, 12 common areas that included kitchens, dining rooms, living rooms, and hallways, seven bathrooms, and two rooms used exclusively as offices. Hodgson et al. ${ }^{21}$ grouped small objects, between 300 and $2000 \mathrm{~cm}^{2}$, into three size bins and counted them instead of measuring each object's dimensions. In addition, they did not measure small miscellaneous objects, less than 300 $\mathrm{cm}^{2}$. Considering the "ventilated" air volume of each room by subtracting the volume of large objects, they reported surface-to-volume ratios ranging from $2.3-5.1 \mathrm{~m}^{-1}$ for bedrooms/offices, $2.3-3.3 \mathrm{~m}^{-1}$ for common areas, $4.6-5.4 \mathrm{~m}^{-1}$ for bathrooms, and $4.6-4.7 \mathrm{~m}^{-1}$ for dedicated offices. A subset of the rooms used in this study were incorporated in Singer et al. ${ }^{23}$ for investigating sorptive partitioning of organic compounds. Summary statistics of the ratios from Hodgson et al. ${ }^{21}$ and others appear in Table 1.1.

\subsubsection{Review of other environmental indoor modeling publications}

In addition to Mueller's and Nazaroff's work, many other experimental and conceptual studies have been conducted to develop mathematical models for predicting indoor pollutant concentration and decay rates. Table 1.1 summarizes the surface-area-to-volume ratios used for each study. 
Table 1.1 - Surface-area-to-volume ratios used in previous experimental and conceptual indoor models

\begin{tabular}{|c|c|c|c|}
\hline Year & Author & Room type & $\begin{array}{l}\text { Surface-to-volume } \\
\text { ratio }\left(\mathbf{m}^{-1}\right)^{\mathrm{a}}\end{array}$ \\
\hline 1983 & Bruno $^{24}$ & Conceptual & 1.8 \\
\hline 1990 & Febo et al. $^{25}$ & Conceptual & $0.5-5.0^{c}$ \\
\hline 1993 & Nazaroff et al. ${ }^{3}$ & Conceptual & $2.8^{\mathrm{b}}$ \\
\hline 1994 & Reiss et al. ${ }^{26}$ & Conceptual & $2.8^{\mathrm{b}}$ and $3.3^{\mathrm{b}}$ \\
\hline 2001 & Thornburg et al. ${ }^{6}$ & Conceptual & 1.75 \\
\hline 1973 & Sabersky et al. ${ }^{12}$ & Test chamber & 4.1 \\
\hline 1997 & Fogh et al. $^{7}$ & Test room (4) & $1.69 \pm 0.25$ \\
\hline \multirow{3}{*}{2002} & \multirow{3}{*}{ Thatcher et al..$^{5}$} & Small experimental room: & \\
\hline & & Unfurnished & 2.4 \\
\hline & & Furnished & $3.2^{\mathrm{b}}$ \\
\hline \multirow{5}{*}{1973} & \multirow{5}{*}{ Mueller et al. ${ }^{13}$} & Aluminum odor test chamber & 5.25 \\
\hline & & Aluminum test room & 3.3 \\
\hline & & Stainless steel test room & 2.69 \\
\hline & & Commercial office & $2.82^{\mathrm{b}}$ \\
\hline & & Bedroom & $3.3^{\mathrm{b}}$ \\
\hline \multirow{2}{*}{2007} & \multirow{2}{*}{ Singer et al. ${ }^{23}$} & Furnished chamber & $2.5^{\mathrm{d}}$ \\
\hline & & Subset of rooms in Hodgson et al. ${ }^{21}$ & $3.9 \pm 0.7$ \\
\hline \multirow{2}{*}{1986} & \multirow{2}{*}{ Nazaroff et al. ${ }^{24}$} & House & 2 \\
\hline & & West wing of a gallery & 1.21 \\
\hline \multirow{2}{*}{1989} & \multirow{2}{*}{ Hayes $^{20}$} & House (conceptual) & 1.8 \\
\hline & & Office (conceptual) & 0.9 \\
\hline 1999 & Abt et al. ${ }^{27}$ & House (3) & $1.71 \pm 0.08$ \\
\hline 2010 & Scheff et al. ${ }^{28}$ & Middle school & $2^{c}$ \\
\hline 1999 & Lee et al. ${ }^{11}$ & Living room & $1.55 \pm 0.43^{\mathrm{b}}$ \\
\hline 2003 & Chao et al. ${ }^{29}$ & Residence (6) & $2.43 \pm 0.16^{\mathrm{b}}$ \\
\hline \multirow{3}{*}{2006} & \multirow{3}{*}{ Hussein et al. ${ }^{30}$} & Entrance hall & $2.1^{\mathrm{b}}$ \\
\hline & & Living room & $3.3^{\mathrm{b}}$ \\
\hline & & Kitchen & $2.7^{\mathrm{b}}$ \\
\hline \multirow{4}{*}{2005} & \multirow{4}{*}{ Hodgson et al. ${ }^{21}$} & Bedroom/office (12) & $3.5 \pm 0.8^{\mathrm{d}}$ \\
\hline & & Common room (12) & $2.8 \pm 0.3^{\mathrm{d}}$ \\
\hline & & Office (2) & $4.7 \pm 0.1^{\mathrm{d}}$ \\
\hline & & Bathroom (7) & $5.0 \pm 0.3^{\mathrm{d}}$ \\
\hline
\end{tabular}

${ }^{a}$ Unless indicated, the surface area and volume do not account for contents. Standard deviation is shown if available.

${ }^{\mathrm{b}}$ All large furnishings included.

${ }^{c}$ Not specified whether contents are included.

${ }^{\mathrm{d}}$ All furnishings and miscellaneous contents larger than $300 \mathrm{~cm}^{2}$ included, and volume is the "ventilated" volume. 


\subsection{Objectives}

The main goal of this thesis research is to characterize the total exposed surface area in different types of rooms, including their contents. This research aims to generate surface-area-to-volume data that can be used for modelling contaminant fate and transport in indoor environments (bedroom, kitchen, and office). More specifically, this project aims to calculate the following metrics for each type of room:

I.Ratio of total surface area with contents to surface area without contents $(S * / S)$

II.Ratio of volume of freely moving air to nominal volume $\left(V^{*} / V\right)$

III. Ratio of surface area to volume without contents $(S / V)$

IV. Ratio of surface area to volume with contents $\left(S^{*} / V^{*}\right)$

V.Shape and materials of the contents

\subsection{References}

1. Klepeis NE, Nelson WC, Ott WR, Robinson JP, Tsang AM, Switzer P, Behar JV, Hern SC and Engelmann WH. The National Human Activity Pattern Survey (NHAPS): a resource for assessing exposure to environmental pollutants. J Expo Anal Env Epid. 2001;11:231-252.

2. National Research Council. Indoor Pollutants. Washington, DC.: The National Academies Press; 1981.

3. Nazaroff WW, Gadgil AJ, Weschler CJ. Critique of the use of deposition velocity in modeling indoor air quality. Am Soc Test Mater. 1993;1205:81-104.

4. Weschler CJ, Shields H, Shah BM. Understanding and reducing the indoor concentration of submicron particles at a commercial building in Southern California. J Air Waste Manage. 1996;46:291-299. 
5. Thatcher TL, Lai ACK, Moreno-Jackson R, Sextro RG, Nazaroff WW. Effects of room furnishings and air speed on particle deposition rates indoors. Atmos Environ. 2002;36:18111819.

6. Thornburg J, Ensor DS, Rodes CE, Lawless PA, Sparks LE, Mosley RB. Penetration of particles into buildings and associated physical factors. Part I: model development and computer simulations. Aerosol Sci Tech. 2001;34:284-296.

7. Fogh CL, Fogh CL, Byrne MA, Roed J, Goddard AJH. Size specific indoor aerosol deposition measurements and derived I/O concentrations ratios. Atmos Environ. 1997;31:2193-2203.

8. Waring MS, Siegel JA. The effect of an ion generator on indoor air quality in a residential room. Indoor air. 2010;21:267-276.

9. Lai ACK. Particle deposition indoors: a review. Indoor air. 2004;12:211-214.

10. Seinfeld JH, Pandis SN. Atmospheric Chemistry and Physics: From Air Pollution to Climate Change. Hoboken, N.J.: J Wiley; 2006.

11. Lee K, Vallarino J, Dumyahn T, Ozkaynak H. Ozone decay rates in residences. J Air Waste Manage. 1999;49:1238.

12. Sabersky RH, Sinema DA, Shair FH. Concentrations, decay rates, and removal of ozone and their relation to establishing clean indoor air. Environ Sci Technol. 1973;7:347-353.

13. Mueller FX, Loeb L, Mapes WH. Decomposition rates of ozone in living areas. Environ Sci Technol. 1973;7:342-346.

14. Wang H Morrison GC. Ozone-initiated secondary emission rates of aldehydes from indoor surfaces in four homes. Environ Sci Technol. 2006;40:5263-5268. 
15. Lioy PJ. Employing dynamical and chemical processes for contaminant mixtures outdoors to the indoor environment: The implications for total human exposure analysis and prevention. $J$ Expo Sci Env Epid. 2006;16:207-224.

16. Weschler CJ, Nazaroff WW. SVOC partitioning between the gas phase and settled dust indoors. Atmos Environ. 2010;44:3609-3620.

17. Weschler CJ, Nazaroff WW. Semivolatile organic compounds in indoor environments. Atmos Environ. 2008;42:9018-9040.

18. Jones PJ, Whittle GE. Computational fluid dynamics for building air flow prediction—current status and capabilities. Build Environ. 1992;27:321-338.

19. Chen Q, Xu W. A zero-equation turbulence model for indoor airflow simulation. Energ Buildings. 1998;28:137-144.

20. Hayes S. Estimating the effect of being indoors on total personal exposure to outdoor air pollution. JAPCA. 1989;39:1453-1461.

21. Hodgson AT, Ming KY, Singer BC, Quantifying object and material surface areas in residences. Lawrence Berkeley National Laboratory; 2005

22. Nazaroff WW, Cass GR. Mathematical modeling of chemically reactive pollutants in indoor air. Environ Sci Technol. 1986;20:924-934.

23. Singer BC, Hodgson AT, Hotchi T, Ming KY, Sextro RG, Wood EE, Brown NJ, Sorption of organic gases in residential rooms. Atmos Environ. 2007;41:3251-3265.

24. Bruno RC. Verifying a model of radon decay product behavior indoors. Health Phys. $1983 ; 45: 471-480$.

25. Febo A, Perrino C. Prediction and experimental evidence for high air concentration of nitrous acid in indoor environments. Atmos Environ A-Gen. 1991;25:1055-1061. 
26. Reiss R, Ryan PB, Koutrakis P. Modeling ozone deposition onto indoor residential surfaces. Environ Sci Technol. 1994;28:504-513.

27. Abt E, Suh HH, Allen G, Koutrakis P. Characterization of indoor particle sources: A study conducted in the metropolitan Boston area. Environ Health Persp. 2000;108:35-44.

28. Scheff PA, Paulius VK, Curtis L, Conroy LM. Indoor air quality in a middle school, part II: development of emission factors for particulate matter and bioaerosols. Appl Occup Environ Hyg. 2000;15:835-842.

29. Chao CYH, Wan MP, Cheng ECK. Penetration coefficient and deposition rate as a function of particle size in non-smoking naturally ventilated residences. Atmos Environ. 2003;37:42334241.

30. Hussein T, Glytsos T, Ondráček J, Dohányosová P, Ždímal V, Hämeri K, Lazaridis M, Smolík J, Kulmala M. Particle size characterization and emission rates during indoor activities in a house. Atmos Environ. 2006;40:4285-4307. 


\section{Chapter 2. Total Surface Area in Indoor Environments}

Archit Manuja ${ }^{1}$, Jenna Ritchie ${ }^{1}$, Yaoxing $\mathrm{Wu}^{2}$, Clara M. A. Eichler ${ }^{1}$, John C. Little ${ }^{1}$, and Linsey C. Marr $^{1}$

${ }^{1}$ Civil and Environmental Engineering, Virginia Tech, 1145 Perry Street, Blacksburg, VA, USA

${ }^{2}$ Environmental Engineering, Texas A\&M University, Kingsville, TX, USA

Key Words: surface, area, volume, built environment, indoor air, deposition

Submitted to Indoor Air in March 2018 


\subsection{Abstract}

Certain processes in indoor air, such as deposition, partitioning, and heterogeneous reactions, involve interactions with surfaces. To accurately describe the surface-area-to-volume ratio in a room, we have characterized the surface area, volume, shape, and material of objects in five bedrooms, four kitchens, and three offices. Averaged over all types of rooms, the ratio of surface area with contents to that without contents was $1.7 \pm 0.2$ (mean \pm standard error), and the ratio of volume of freely moving air to volume of the entire space was $0.89 \pm 0.05$. Ignoring contents, the surface-area-to-volume ratio was $1.9 \pm 0.3 \mathrm{~m}^{-1}$; accounting for contents, the ratio was $3.7 \pm 1.2 \mathrm{~m}^{-}$

1. Ratios were not significantly different between room types and were comparable to those measured for 33 rooms in a similar study. Due to substantial differences in the design and contents of kitchens, their ratios had the highest variability among the three room types. The most common shape of objects in a room was a flat plate, while each room also had many irregularly-shaped objects. Paint and wood were the two most common materials in each room, although the distribution of materials varied by room type.

\subsection{Practical Implications}

In a room containing objects, the surface area that is relevant for interactions with indoor air is larger than that of the walls, floor, and ceiling alone. Objects such as furniture, window coverings, books, and clothing contribute to surface area while subtracting from the volume of freely moving air. On average, the contents of bedrooms, kitchens, and offices increase their surface area by $70 \%$ and decrease their volume of freely moving air by $11 \%$ compared to an empty room. The results 
of this study can be used to improve understanding of the behavior of gases and particles in indoor environments.

\subsection{Introduction}

Since humans spend over $87 \%$ of their time indoors, on average, ${ }^{1}$ understanding indoor air quality is essential for characterizing the relationship between health and the environment. Conceptual and numerical models are important tools for understanding the transport, transformation, and fate of gases and particles indoors. Among the inputs to such models are the surface area and volume of the indoor setting, often combined as the surface-area-to-volume ratio or the surface-to-volume ratio, yet researchers often assume that the surface area and volume of a room are determined by the dimensions of its walls, floor, and ceiling while ignoring the contribution of any contents of the room. There have been some exceptions that considered real-world rooms and accounted for at least the major furnishings. ${ }^{2,3,4}$

For processes such as deposition, partitioning, and heterogeneous reactions, surface area plays a critical role. Deposition of gases and particles onto surfaces removes them from the air, thus eliminating inhalation exposure to them. However, deposition on surfaces can cause detrimental effects both directly, such as deterioration of materials ${ }^{5}$ and damage to electrical equipment ${ }^{6}$ by particles, and indirectly, such as ozone-induced secondary emissions of aldehydes from indoor surfaces. ${ }^{7}$ Semi-volatile compounds partition between the gas phase and the condensed phase, in which they are usually adsorbed on surfaces. ${ }^{8,9}$ In addition, surfaces can be a source of emissions of gases and particles. Heterogeneous reactions, such as between nitrous acid and nicotine to form 
carcinogenic nitrosamines, ${ }^{10}$ take place at the gas-surface interface. At a gross level, these processes do not discriminate between the surface area of walls and that of objects in the room.

Mass-balance equations are widely used to model concentrations of gases or particles in a room. As shown in Equation (1), a typical model accounts for advective transport into and out of the room, emissions, loss by reaction, and loss by deposition, where $C$ is the concentration of the contaminant inside the room, $V$ is the volume of the room, $Q$ is the volume flow rate of air into and out of the room, $C_{\text {out }}$ is the concentration immediately outside the room, $E$ is the emission rate, $k$ is the first-order reaction rate coefficient, $v_{d}$ is the deposition velocity, and $S$ is the surface area of the room.

$$
\frac{d(C V)}{d t}=Q C_{\text {out }}-Q C+E-k C V-v_{d} S C
$$

Dividing through by $V$ produces the surface-to-volume ratio $(S / V)$ in the last term. In theory, $S$ should be the total surface area accessible to the contaminant, and $V$ should be the volume of freely moving air in the room.

The most comprehensive study of total surface area in rooms appears in a report by Hodgson et al. ${ }^{11}$ They systematically measured all objects larger than $300 \mathrm{~cm}^{2}$ (about the surface area of a soda can) in 33 rooms in nine residences, encompassing 12 bedrooms that also functioned as offices, 12 common areas that included kitchens, dining rooms, living rooms, and hallways, seven bathrooms, and two rooms used exclusively as offices. Considering the "ventilated" air volume of each room by subtracting the volume of large objects, they reported surface-to-volume ratios ranging from $2.3-5.1 \mathrm{~m}^{-1}$ for bedrooms/offices, $2.3-3.3 \mathrm{~m}^{-1}$ for common areas, $4.6-5.4 \mathrm{~m}^{-1}$ for bathrooms, and $4.6-4.7 \mathrm{~m}^{-1}$ for dedicated offices. Summary statistics of the ratios from Hodgson et al. ${ }^{11}$ and others appear in Table 2.1. Additionally, Mueller et al. ${ }^{4}$ calculated the surface-to- 
volume ratio in four indoor environments: an aluminum odor test facility $\left(5.3 \mathrm{~m}^{-1}\right)$, metal test rooms (stainless steel: $2.7 \mathrm{~m}^{-1}$, aluminum: $\left.3.3 \mathrm{~m}^{-1}\right)$, an office $\left(2.8 \mathrm{~m}^{-1}\right)$, and a home $\left(3.3 \mathrm{~m}^{-1}\right)$. These ratios included the surface area of the contents in each indoor environment. In a critique of the use of the deposition velocity in conceptual models, Nazaroff ${ }^{5}$ assumed a "typical" $S / V$ value of 2.8 $\mathrm{m}^{-1}$. Many subsequent studies have used either Mueller's ${ }^{4}$ ratios or Nazaroff' $\mathrm{s}^{5}$ "typical" value of $S / V$, and some have reported other values accounting for varying fractions of the room contents.

In addition to the surface area of the contents of a room, the type of material, dimensions, and orientation of the contents may also be important for certain processes. For example, the deposition velocity of a gas depends on its solubility in and reactivity with the surface. ${ }^{12}$ Air flow dynamics models may be used to understand indoor environmental quality, such as evaluating the effectiveness of heating, cooling, and ventilation systems in a building ${ }^{13}$ or predicting personal exposure to pollutants. Realistic simulations of air flow indoors require accounting for the size, shape, and orientation of the objects in a room.

The objective of this research is to characterize the contents of three different types of roomsbedrooms and kitchens in residences and offices in a university building - in terms of exposed surface area, volume, shape, and material composition. We selected bedrooms and offices because people spend large amounts of time in these types of rooms, and we selected kitchens because they are the site of cooking-related emissions of gases and particles that have implications for health and indoor chemistry. ${ }^{9,14,15,16}$ We calculated surface-to-volume ratios including and excluding the contents present in the room. Results of this study can be used to improve models of the transport, transformation, and fate of gases and particles in indoor air. 
Table 2.1. Surface-to-volume ratios of indoor environments in previous studies and this study, grouped roughly by type of room and whether contents are included.

\begin{tabular}{|c|c|c|c|}
\hline Year & Author & Room type & $\begin{array}{l}\text { Surface-to-volume } \\
\text { ratio }\left(\mathbf{m}^{-1}\right)^{\mathrm{a}}\end{array}$ \\
\hline 1983 & Bruno $^{17}$ & Conceptual & 1.8 \\
\hline 1990 & Febo et al. ${ }^{18}$ & Conceptual & $0.5-5.0^{c}$ \\
\hline 1993 & Nazaroff et al. ${ }^{5}$ & Conceptual & $2.8^{\mathrm{b}}$ \\
\hline 1994 & Reiss et al. ${ }^{19}$ & Conceptual & $2.8^{\mathrm{b}}$ and $3.3^{\mathrm{b}}$ \\
\hline 2001 & Thornburg et al. ${ }^{20}$ & Conceptual & 1.75 \\
\hline 1973 & Sabersky et al. ${ }^{21}$ & Test chamber & 4.1 \\
\hline 1997 & Fogh et al. ${ }^{22}$ & Test room (4) & $1.69 \pm 0.25$ \\
\hline \multirow{3}{*}{2002} & \multirow{3}{*}{ Thatcher et al. ${ }^{23}$} & Small experimental room: & \\
\hline & & Unfurnished & 2.4 \\
\hline & & Furnished & $3.2^{\mathrm{b}}$ \\
\hline \multirow{5}{*}{1973} & \multirow{5}{*}{ Mueller et al. ${ }^{4}$} & Aluminum odor test chamber & 5.25 \\
\hline & & Aluminum test room & 3.3 \\
\hline & & Stainless steel test room & 2.69 \\
\hline & & Commercial office & $2.82^{\mathrm{b}}$ \\
\hline & & Bedroom & $3.3^{\mathrm{b}}$ \\
\hline \multirow{2}{*}{2007} & \multirow{2}{*}{ Singer et al. ${ }^{24}$} & Furnished chamber & $2.5^{\mathrm{d}}$ \\
\hline & & Subset of rooms in Hodgson et al. ${ }^{11}$ & $3.9 \pm 0.7$ \\
\hline \multirow{2}{*}{1986} & \multirow{2}{*}{ Nazaroff et al. ${ }^{25}$} & House & 2 \\
\hline & & West wing of a gallery & 1.21 \\
\hline \multirow{2}{*}{1989} & \multirow{2}{*}{ Hayes $^{26}$} & House (conceptual) & 1.8 \\
\hline & & Office (conceptual) & 0.9 \\
\hline 1999 & Abt et al. ${ }^{27}$ & House (3) & $1.71 \pm 0.08$ \\
\hline 2010 & Scheff et al. ${ }^{28}$ & Middle school & $2^{c}$ \\
\hline 1999 & Lee et al. ${ }^{3}$ & Living room & $1.55 \pm 0.43^{b}$ \\
\hline 2003 & Chao et al. ${ }^{2}$ & Residence (6) & $2.43 \pm 0.16^{\mathrm{b}}$ \\
\hline \multirow{3}{*}{2006} & \multirow{3}{*}{ Hussein et al. ${ }^{29}$} & Entrance hall & $2.1^{\mathrm{b}}$ \\
\hline & & Living room & $3.3^{\mathrm{b}}$ \\
\hline & & Kitchen & $2.7^{\mathrm{b}}$ \\
\hline \multirow{4}{*}{2005} & \multirow{4}{*}{ Hodgson et al. ${ }^{11}$} & Bedroom/office (12) & $3.5 \pm 0.8^{\mathrm{d}}$ \\
\hline & & Common room (12) & $2.8 \pm 0.3^{\mathrm{d}}$ \\
\hline & & Office (2) & $4.7 \pm 0.1^{\mathrm{d}}$ \\
\hline & & Bathroom (7) & $5.0 \pm 0.3^{\mathrm{d}}$ \\
\hline \multirow{6}{*}{2018} & \multirow{6}{*}{$\begin{array}{l}\text { Manuja et al. (this } \\
\text { study) }\end{array}$} & Bedroom (5) without contents & $2.0 \pm 0.3$ \\
\hline & & Kitchen (4) without contents & $1.9 \pm 0.6$ \\
\hline & & Office (3) without contents & $1.9 \pm 0.1$ \\
\hline & & Bedroom (5) with contents & $3.3 \pm 0.4^{\mathrm{e}}$ \\
\hline & & Kitchen (4) with contents & $4.3 \pm 2.4^{\mathrm{e}}$ \\
\hline & & Office (3) with contents & $3.6 \pm 0.4^{\mathrm{e}}$ \\
\hline
\end{tabular}

${ }^{a}$ Unless indicated, the surface area and volume do not account for contents. Standard deviation is shown if available. 
${ }^{\mathrm{b}}$ All large furnishings included.

${ }^{\mathrm{c}}$ Not specified whether contents are included.

${ }^{\mathrm{d}}$ All furnishings and miscellaneous contents larger than $300 \mathrm{~cm}^{2}$ included, and volume is the "ventilated" volume.

${ }^{\mathrm{e}}$ All furnishing and miscellaneous contents included, and volume is that of freely moving air.

\subsection{Materials and Methods}

2.4.1 Experimental metrics. We defined the surface area of a room excluding its contents as $S$ (i.e., walls, floor, and ceiling only), the surface area with contents as $S^{*}$, the total volume of the room as $V$, equal to length $(L) \times$ width $(W) \times$ height $(H)$, and the volume of freely moving air in the room, described in more detail below, as $V^{*}$. Using these definitions, we calculated four metrics: (1) ratio of total surface area with contents to surface area without contents $(S * / S)$, ratio of volume of freely moving air to nominal volume $\left(V^{*} / V\right),(2)$ ratio of surface area to volume without contents $(S / V)$, and (4) ratio of surface area to volume with contents $\left(S^{*} / V^{*}\right)$. If the room is empty, then $S^{*}$ equals $S$, and the ratio $S^{*} / S$ equals 1 , and likewise for $V^{*}$ and $V$. If the contents of the room have the same amount of surface area as the walls, floor, and ceiling, then $S * / S$ equals 2. As ceiling heights are usually similar across different types of rooms, if no contents are present in a room, a smaller room (in length and width) will have a larger $S / V$ compared to a larger room.

Surface area can vary with resolution. For example, we could measure the surface area of a rectangular carpet as the projected $L \times W$, but we could also consider the surface area of each piece of yarn or even of each fiber making up the yarn and so on. We employed a resolution of $\sim 1 \mathrm{~cm}$ in our measurements, or what could readily be discerned using a measuring tape. While some processes of interest involve individual molecules, in which case nanoscale resolution would be most appropriate, it is simply not feasible at this stage to measure surface area in a room at this scale. 
2.4.2 Indoor environments. We considered three different types of rooms that are frequently modeled in studies of indoor environments: bedrooms, kitchens, and offices. Through a convenience sampling approach that aimed to capture diversity in building style and age of residences, we selected for analysis five bedrooms, including one belonging to a child, and four kitchens in residences in Blacksburg, Virginia and three offices with different layouts in a university building at Virginia Tech. The residential buildings included multi-family units and single-family homes. The categorization and types of rooms differed from those described by Hodgson et al. ${ }^{11}$. All of the bedrooms in the previous study also functioned as an office for the occupants, and the two offices were in residences. In the present study, all bedrooms primarily functioned as bedrooms, and only 2 of them contained a desk and chair. Hodgson et al. ${ }^{11}$ included kitchens as part of the common area, which also included living and dining rooms, hallways, and foyers, whereas our study focused on kitchens separately from all other common areas.

2.4.3 Measurement techniques. We measured the dimensions of walls, floors, ceilings, and individual contents of the room using a measuring tape. For rectangular objects, we measured $L$, $W$, and $H$ and used these to calculate surface area and volume. For cylindrical, conical, and spherical objects, we measured the diameter as well and used the appropriate equations to calculate surface area and volume. We applied the appropriate geometric equations where possible for other shapes. For irregularly shaped objects, we quantified them as the sum of component 2D or 3D shapes, such as rectangles, triangles, cones, etc., applied the appropriate geometric equation to estimate the surface area, and volume, of each part, and then summed the parts. For especially complex contents, such as a mask or coffee maker, we estimated the surface area and volume to the best of our ability. We only calculated the exposed surface area of objects, meaning the area 
which was in direct contact with the bulk air in the room. For example, if a box was on the floor, we did not calculate the surface area of the bottom of the box.

The main difference between this approach and Hodgson et al.' ${ }^{11}$ is the handling of small objects. Hodgson et al. ${ }^{11}$ grouped small objects, between 300 and $2000 \mathrm{~cm}^{2}$, into three size bins and counted them instead of measuring each object's dimensions. In addition, they did not measure small miscellaneous objects, less than $300 \mathrm{~cm}^{2}$, approximately the size of soda can. In contrast, we measured all miscellaneous contents regardless of their size. In addition, we also subtracted the volume of large objects, such as beds, cabinets, and appliances, and small miscellaneous objects, such as clocks, boxes, and cans, to obtain an estimate of the volume of the freely moving air inside the room. We were unable to calculate the volume of some small contents with surface area less than $\sim 100 \mathrm{~cm}^{2}$, due to their irregular shapes.

We also recorded the shape and the material of all objects. For those consisting of more than one material, we calculated the surface area of each different material separately. We categorized the shapes as either cylinder, flat plate, open top containers, rectangular prism, sphere, or irregular. We categorized the materials as either cardboard, concrete, fabric, fiber, glass, marble, metal, paint, paper, plastic, wood (stained), or other. All the closets, drawers, and cabinets in the rooms were closed, and thus, we did not measure the surface area of the objects inside them.

2.4.4 Statistical analysis. We compared $S * / S, V * / V, S / V$, and $S * / V^{*}$ among the three types of rooms. Because we did not expect the variances for the three types of rooms to be similar, we performed the non-parametric Kruskal-Wallis test to evaluate differences among rooms. In addition, we performed a Shapiro-Wilks test on the residuals to verify that the data points were normally distributed. We produced a normal quantile-quantile plot using all 12 rooms to visually evaluate the distribution of the data. We used an alpha of 0.05 for all statistical tests. 


\subsection{Results}

We analyzed a total of 12 rooms listed in Table 2.2. These included five bedrooms, one of which belonged to a child, and four kitchens in residences and three offices in a university building. Each of the five bedrooms contained a bed consisting of a frame, mattress, linens, and pillows and a closet. Other typical bedroom contents, such as tables, chairs, posters, cabinets, fans, storage boxes, and books, were present in variable quantities among the five bedrooms. All bedrooms had at least one window. Bedrooms 1 and 2 contained full-sized beds, bedrooms 3 and 5 contained king-sized beds, and bedroom 4 contained a twin-sized bed.

All four kitchens contained a refrigerator, microwave, oven and stove, cabinets, garbage can, and sink. Kitchens 2 and 4 were larger than 1 and 3, and contained an eating area with a dining table and chairs, along with additional contents such as stools, a pantry, and a toaster oven. Only kitchen 4 had windows. The kitchens typically had only two or three walls and were open to other rooms in the residence.

All three offices contained desks, chairs, computers, multiple shelves, cabinets, books, and common office supplies. Although all offices analyzed were located in the same building, they varied in size and style. One of the walls in offices 1 and 2 was composed primarily of windows, while office 3 did not have any windows. Office 2 was a corner office and was larger than the others. As office 3 was shared by three people, it had three desks, three chairs, and multiple shelves. 
Table 2.2. Dimensions, surface area without $(S)$ and with $\left(S^{*}\right)$ contents, volume without $(V)$ and with $\left(V^{*}\right)$ contents, and ratios for bedrooms, kitchens, and offices.

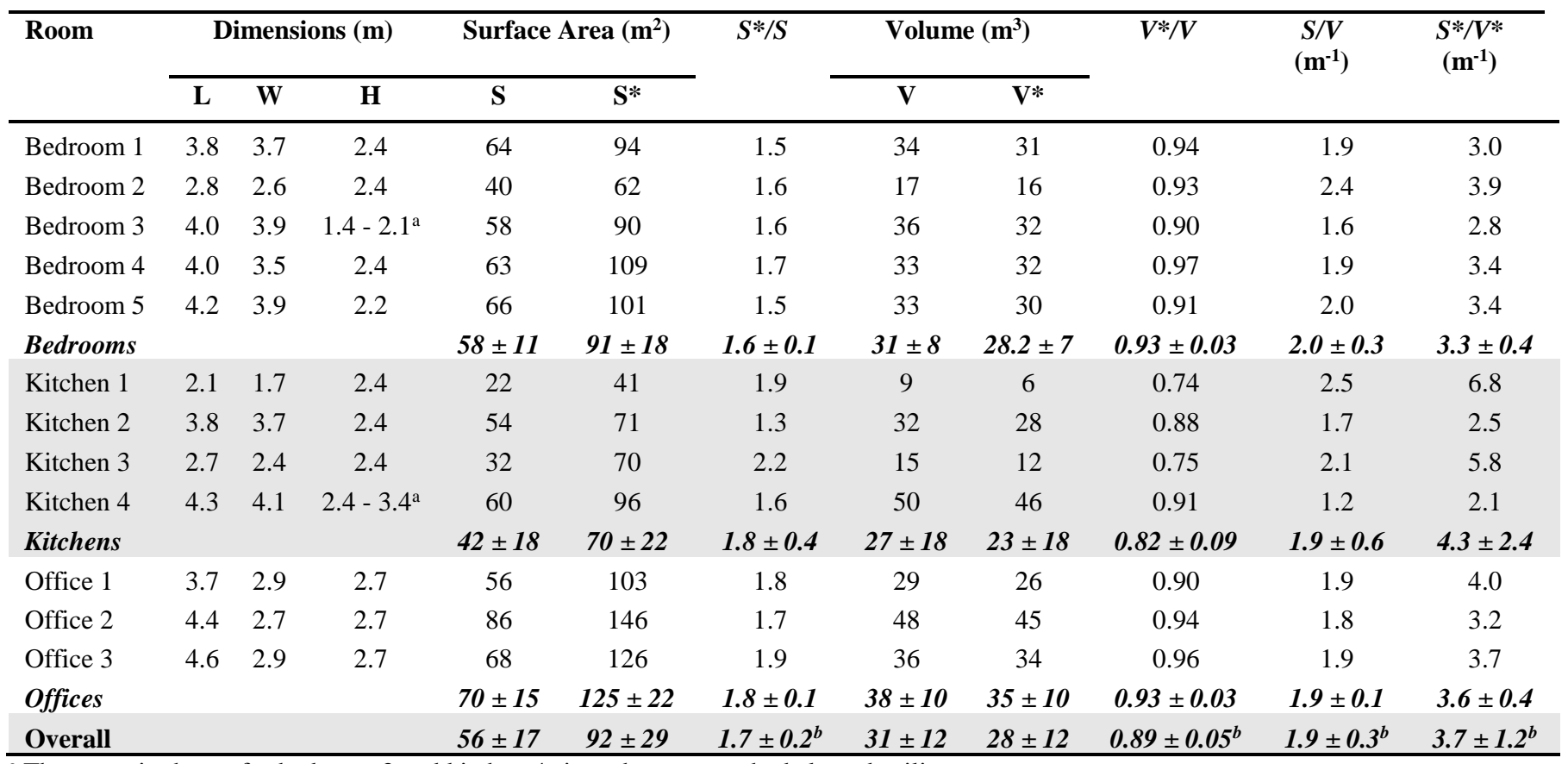

a The range is shown for bedroom 3 and kitchen 4 since these rooms had slanted ceilings.

${ }^{\mathrm{b}}$ Mean and standard error across room types.

Among all rooms studied, the length and width ranged from 2.4 to $4.6 \mathrm{~m}$, and the ceiling height ranged from 2.1 to $3.1 \mathrm{~m}$; however, it was 2.4 or $2.7 \mathrm{~m}$ for most rooms, as shown in Table 2.2. Bedroom 3 and kitchen 4 had slanted ceilings. The volume of the rooms ranged from 9 to $50 \mathrm{~m}^{3}$. On average, kitchens were smaller in volume than bedrooms and offices but also had the largest variability in volume. Three of the bedrooms had nearly the same volume, while bedroom 2 was significantly smaller. Kitchens 2 and 4 were substantially larger than kitchens 1 and 3 . The volume of the offices varied widely.

Table 2.2 shows that the surface area without contents, $S$, ranged from 22 to $86 \mathrm{~m}^{2}$. Typically, rooms with larger volume had larger $S$, although this was not always true. Although bedroom 3 had a slightly larger volume than bedroom 1, it had a slightly smaller $S$. The surface area with contents, $S^{*}$, ranged from 41 to $146 \mathrm{~m}^{2}$. In most cases, a room with a larger $S$ also had a larger $S^{*}$. 
An exception was that bedroom 5 had a slightly larger $S$ than bedroom 4, whereas $S^{*}$ for bedroom 4 was slightly larger than that for bedroom 5. Generally, kitchens had a smaller $S$ and $S^{*}$ than bedrooms and offices.

$S * / S$ for the all but two rooms fell in the range of 1.5 to 1.9 , so the contents of these rooms added $50 \%$ to $90 \%$ of the surface area of the walls, floor, and ceiling. The ratios for kitchens 2 and 3 fell outside this range. Quite similarly, $V * / V$ for all but two rooms fell in the range 0.88 to 0.97 , so the contents of these rooms (a different subset than discussed for surface area) occupied $3 \%$ to $12 \%$ volume of the room. The ratios for kitchens 1 and 3 were lower than this range due to their small size. Figure 2.1 shows the mean $S * / S$ and mean $V * / V$ for each type of room. Both ratios were not significantly different among room types. Across all room types, the mean $S * / S$ was 1.7 , and the mean $V^{*} / V$ was 0.89 .

The ratio $S / V$ for nine of the rooms fell in the range of 1.6 to $2.1 \mathrm{~m}^{-1}$, and the mean across all types of rooms was $1.9 \mathrm{~m}^{-1}$. As accounting for contents increases the surface area and reduces the volume compared to an empty room, $S^{*} / V^{*}$ was larger; the mean across room types was $3.7 \mathrm{~m}^{-1}$. The variability in $S * / S, V^{*} / V, S / V$, and $S^{*} / V^{*}$ was highest for the kitchens due to greater differences in size and contents compared to that found in bedrooms and offices. As shown in Figure 2.1, $S / V$ and $S * / V^{*}$ were similar across all types of rooms.

Figure 2.2 shows that in terms of shape, the majority of surface area in the rooms, except for kitchens 1 and 3, was a flat surface. Besides the walls, floor, and ceiling, other flat surfaces included cabinets attached to walls, closet doors, and windows. The second most common shape was a rectangular prism, usually dominated in bedrooms by the bed, shelves, cabinets, and storage boxes. In kitchens, the microwave, oven, and refrigerator were counted as rectangular prisms. In 
offices, the majority of surfaces were also flat; however, more of the surface area was associated with irregularly shaped objects than with rectangular prisms.

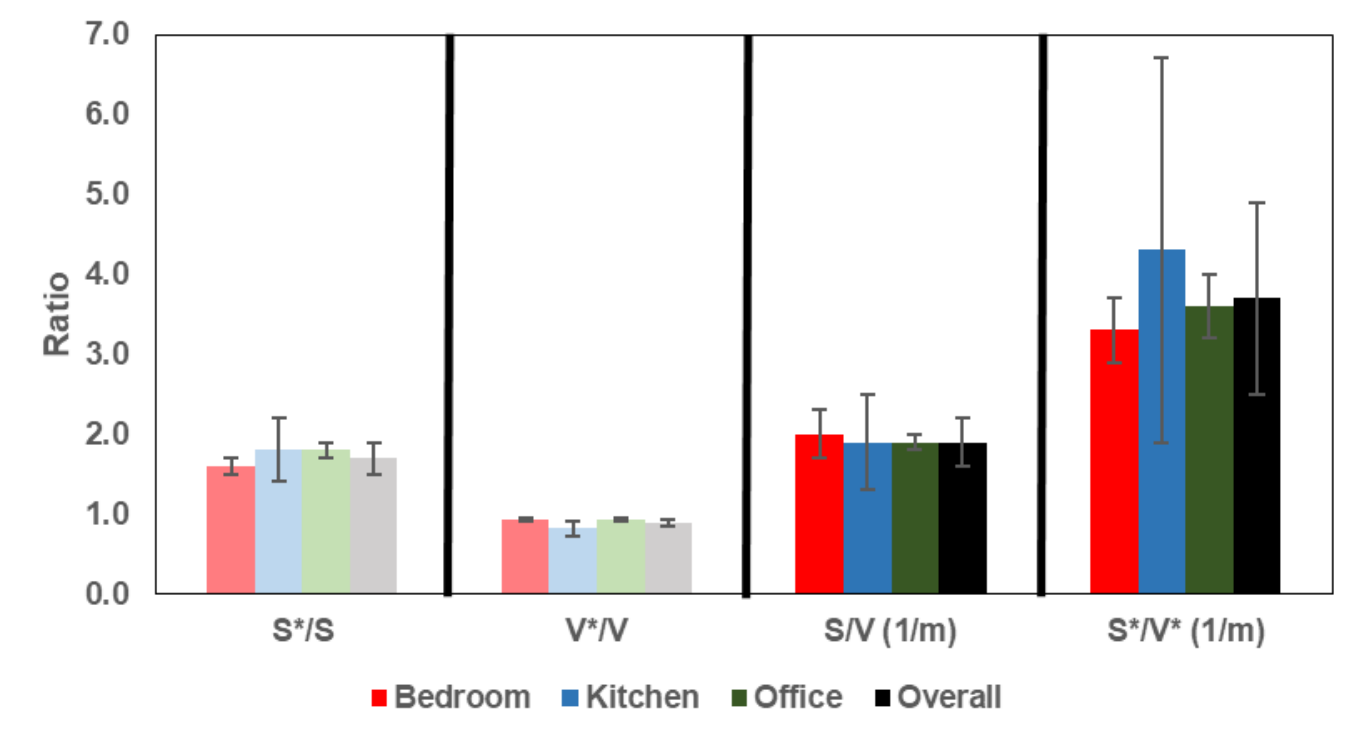

Figure 2.1. Ratios (mean \pm standard deviation) of surface area with contents to surface area without contents $\left(S^{*} / S\right)$; volume with contents to volume without contents $\left(V^{*} / V\right)$; surface area to volume without contents $(S / V)$; surface are area volume with contents $\left(S^{*} / V^{*}\right)$ for each type of room, and overall ratios (mean \pm standard error) for all three room types combined. 


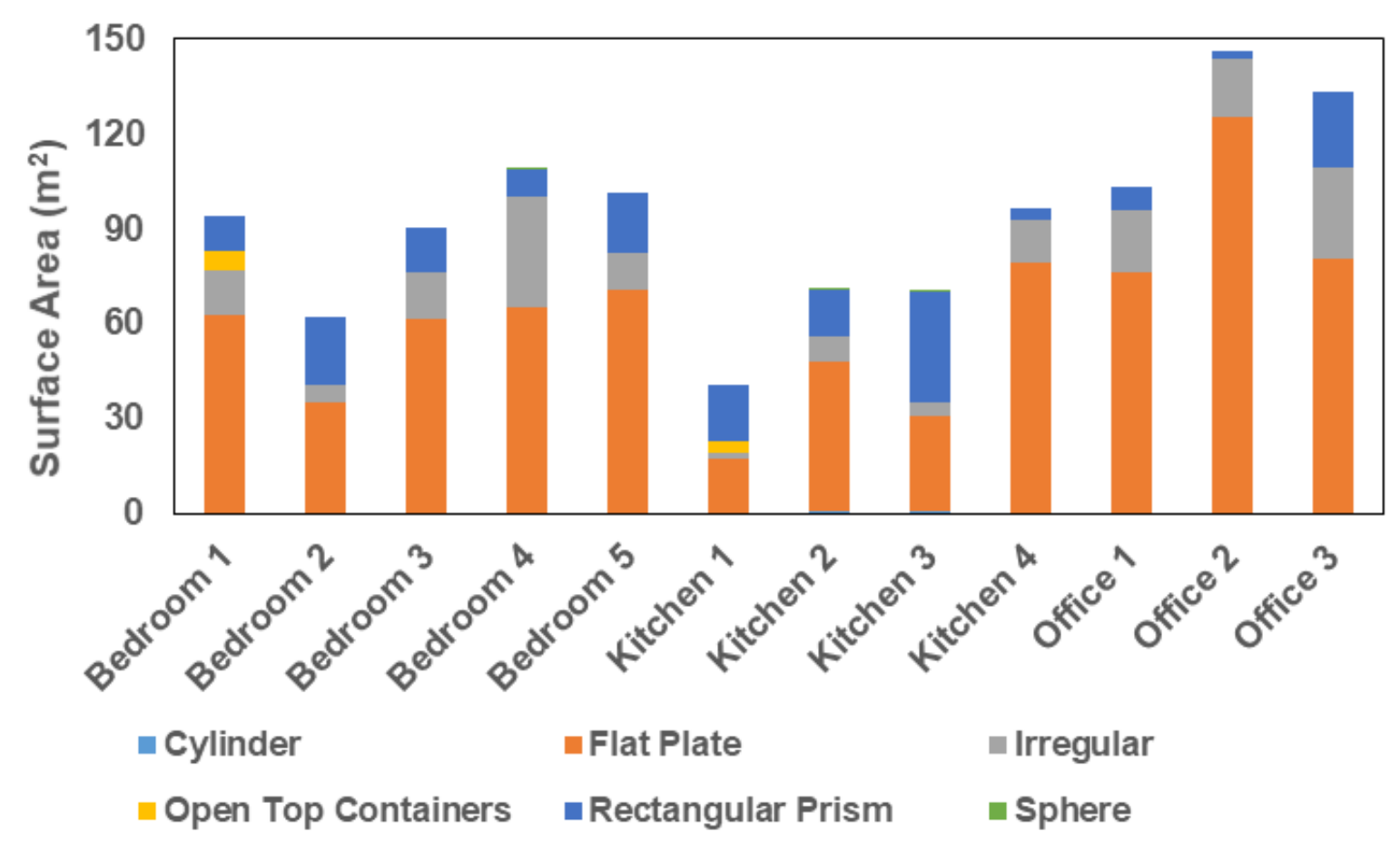

Figure 2.2. Surface area by shape of all contents in each room.

As shown in Figure 2.3, paint was generally the most common type of surface present in the rooms, largely due to walls and ceilings. The floor was usually either made of fibrous material (i.e., carpet), wood, marble, or vinyl flooring. In some cases, such as bedroom 3, wood was the most common material, as parts of the walls and the ceiling were constructed using wood. The wood was stained but otherwise not painted. Plastic was also relatively common, especially in offices. Many of the miscellaneous contents were comprised of plastic, glass, fabric, metal, or other materials, although most of these contents were relatively small in size, and did not significantly influence the overall material composition. 


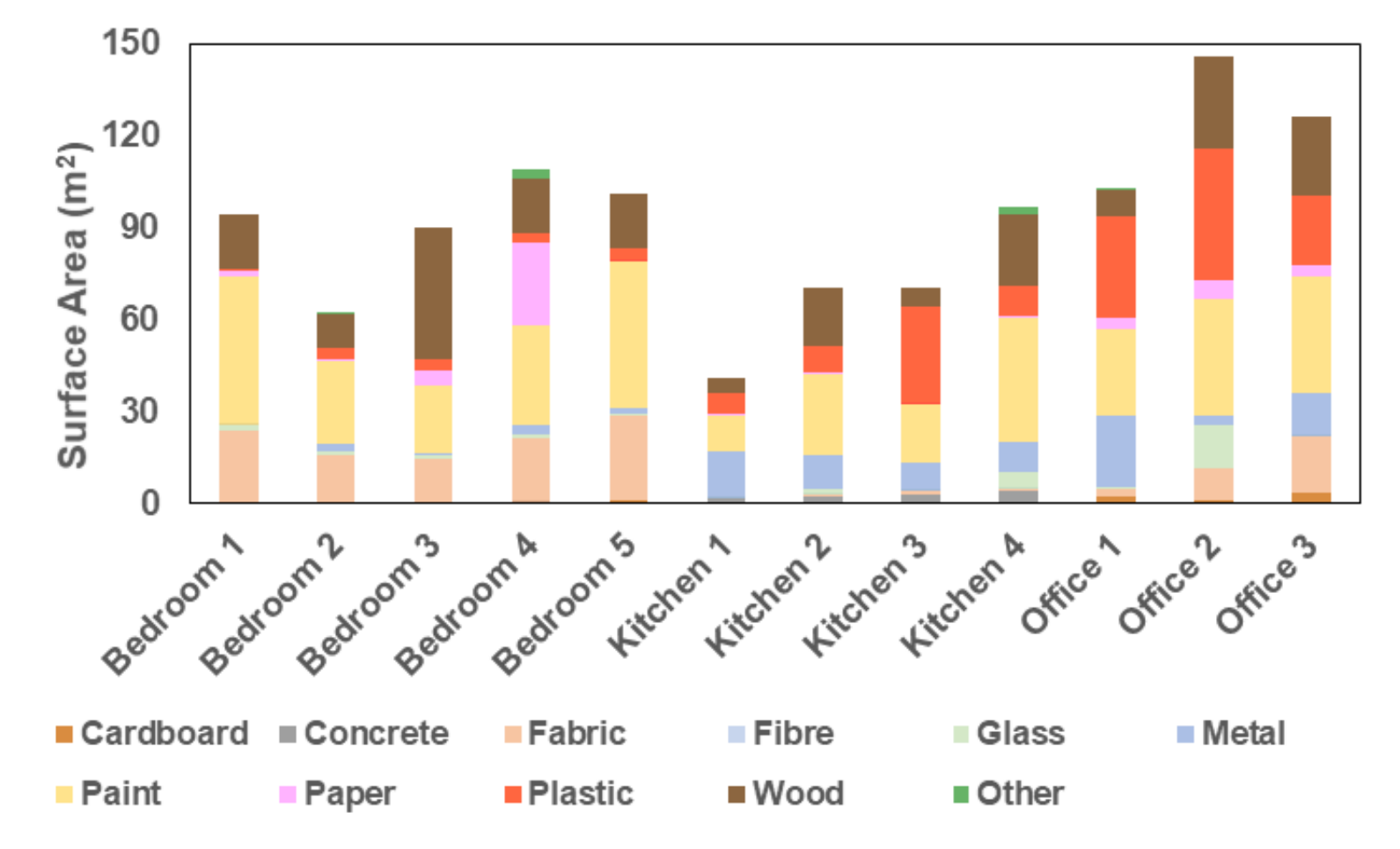

Figure 2.3. Surface area by material of all contents in each room.

\subsection{Discussion}

In considering interactions between gases, particles, and surfaces indoors, we should not overlook the contribution of a room's contents to surface area. The average $S * / S$ ratio of 1.7 determined in this study means that objects in a room increase its surface area by $70 \%$ beyond that of the walls, floor, and ceiling alone. The average $V^{*} / V$ ratio of 0.89 means that objects in a room decrease the volume of freely moving air by $11 \%$. Of all the numerical metrics presented (i.e., $S * / S, V * / V, S / V$, and $\left.S^{*} / V^{*}\right), S^{*} / S$ and $V^{*} / V$ were the two least variable, so we recommend that researchers who apply the results of this study first calculate $S$ and $V$ for their scenario either from measurements or architectural drawings, then estimate $S^{*}$ and $V^{*}$ using these ratios to estimate $S^{*} / V^{*}$. 
As the large furnishings or appliances were similar across rooms, variability in surface area was attributable mainly to miscellaneous contents. Typically, a neat room would have more open space and more organized contents than a messy room. A guest bedroom may have fewer miscellaneous contents in addition to the essentials (bed, closet, lights, etc.), whereas a child's bedroom may be less organized with more miscellaneous contents. In general, a messy room would typically have a higher $S * / S$ ratio. In addition to size and shape, the orientation of the contents can affect the amount of exposed surface area in a room. For example, the exposed surface area of rectangular box with a high aspect ratio changes when the box is flipped on its side.

In this study, we did not account for any of the contents present inside the closets, drawers, and cabinets. If any of the closets, drawers, or cabinets were open, $S * / V^{*}$ would increase since the objects present within them would increase the amount of surface available for interactions with particles and gases in the bulk room air. Although small open cabinets or drawers may only increase $S * / V^{*}$ slightly, an open walk-in closet could potentially skyrocket the ratio. Similarly, we did not account for humans present in the room. The surface area of an average human ${ }^{30}$ is 1.70 $\mathrm{m}^{2}$, which is negligible compared to the observed values of $S^{*}$. However, if several people were present in a room, such as in a classroom or during a party, their surface area could raise $S^{*} / V^{*}$ significantly.

We measured surface area at a resolution of $\sim 1 \mathrm{~cm}$, much larger than the scale pertinent to gases and particles. Measuring objects with higher resolution would produce much larger values of $S^{*}$ and $S * / V^{*}$. Using atomic force microscopy with a resolution of $\sim 5 \mathrm{~nm}$, we previously showed that the surface area of smooth, flat materials including glass, aluminum, plastic, and stainless steel was up to 2.1 times higher than the projected surface area. ${ }^{9}$ The difference would be much higher for "rougher" materials, especially fibrous ones such as carpets. 
The $S / V$ and $S^{*} / V^{*}$ ratios calculated in this study are consistent with those in the literature, as summarized in Table 2.1. In previous studies that have assessed the same types of rooms considered here, $S / V$ ranged from 1.5 to $3.9 \mathrm{~m}^{-1}$. The values of $S / V$ and $S * / V^{*}$ calculated in this study are within this range as well. Compared to a similar study by Hodgson et al., ${ }^{11}$ our $S^{*} / V^{*}$ ratio is $6 \%$ lower for bedrooms, and our overall $S^{*} / V^{*}$ ratio for all types of rooms, $3.7 \mathrm{~m}^{-1}$, is only $3 \%$ higher, even though the types of rooms measured in the two studies differ. The good agreement between the two studies suggests that their results from a combined 44 rooms may be broadly representative. Our overall mean $S * / V *$ ratio is $24 \%$ higher than the "typical" value of $S / V$ used by Nazaroff et al. ${ }^{5}$ However, our mean $S * / V^{*}$ ratio for bedrooms is equal to the $S * / V$ ratio for the bedroom calculated by Mueller et al. ${ }^{4}$ and our mean $S^{*} / V^{*}$ ratio for offices is $22 \%$ higher than $S^{*} / V$ ratio for the office calculated by Mueller et al. ${ }^{4}$

Measuring all the contents of a room is time-consuming and tedious, so the question arises, "How many objects do we need to measure to capture most of the surface area?" Figure 2.4 shows the cumulative surface area in each room as a function of the number of objects ordered from largest to smallest in terms of surface area. The number of objects that contribute to $90 \%$ of the exposed surface area, indicated by the dashed line, ranges from nine to 20 and averages 14 . In this enumeration, each wall, the floor, and the ceiling count as a different object, so these would account for six objects in a typical room. As volume incorporates another dimension, the smaller objects are even less important in estimating the total volume of objects in a room to calculate the volume of freely moving air. Another labor-saving approach might be to use image processing or Light Detection and Ranging (LIDAR) to measure surface area, although these would require considerable method development. 


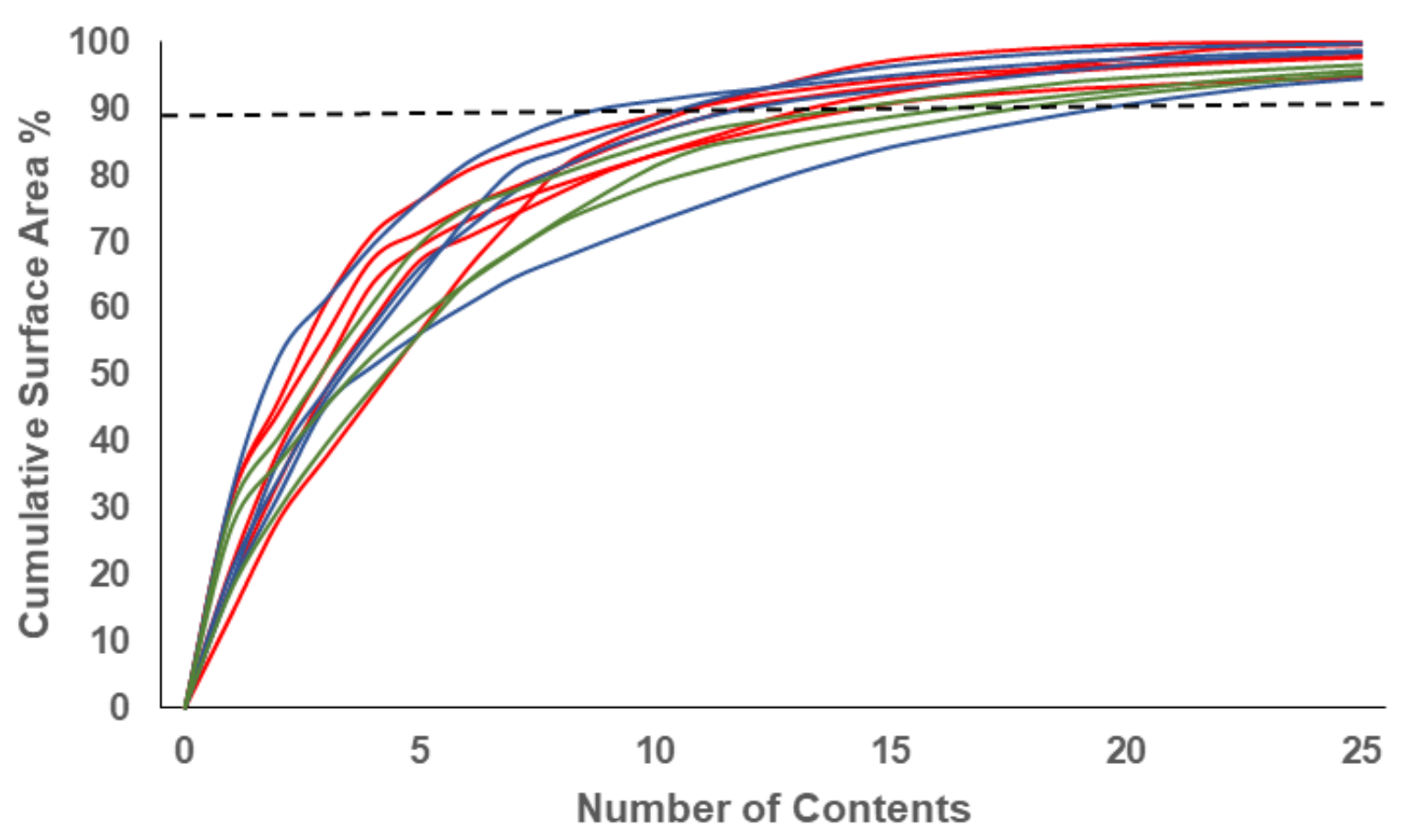

Figure 2.4. Number of contents, including floor, ceiling, and each wall, required to achieve a certain amount of the total exposed surface area. Red is bedrooms, blue is kitchens, and green is offices. The dashed line indicates $90 \%$ of the total surface area.

\subsection{Conclusions}

We measured the surface-to-volume ratio, including and excluding contents, of five bedrooms, four kitchens, and three offices, in buildings in Virginia. Across all types of rooms, the average ratio of surface area with contents to that without, $S * / S$, was $1.7 \pm 0.2$ (mean \pm standard error), meaning that the contents of a room contributed to the total surface area another $70 \%$ beyond the area of the walls, floor, and ceiling. The average ratio of volume of freely moving air to volume of the entire room, $V^{*} / V$, was $0.89 \pm 0.05$, meaning that the contents occupied only about $11 \%$ of space in a room. $S / V$ was $1.9 \pm 0.3 \mathrm{~m}^{-1}$, and $S^{*} / V^{*}$ was $3.7 \pm 1.2 \mathrm{~m}^{-1}$, nearly two times higher 
compared to the ratio that ignores contents. These ratios were not significantly different by type of room. Generally, the amount of miscellaneous contents beyond major furnishings and appliances dictated $S^{*} / V^{*}$, and messier rooms had a higher $S^{*} / V^{*}$. While these measurements contribute new information about surface area indoors, they underestimate the true surface area that is accessible to gases and particles, as we necessarily used a resolution of $\sim 1 \mathrm{~cm}$. The largest $9-20$ objects in a room accounted for $90 \%$ of its total surface area.

We also characterized the shape and material of objects in the rooms. The majority of objects were flat surfaces, dominated by walls, floor, ceiling, cabinets, closet doors, and windows. Paint was typically the most common surface type, largely due to walls and ceilings. This information can be used to improve models of the fate and transport of gases and particles in indoor environments.

\subsection{Acknowledgments}

This research was supported by the United States Environmental Protection Agency (RD83560601-0) and a National Institutes of Health New Innovator Award (1-DP2-A1112243). The authors thank Gabriel Isaacman-VanWertz for feedback on the research.

\subsection{References}

1. Klepeis NE, Nelson WC, Ott WR, Robinson JP, Tsang AM, Switzer P, Behar JV, Hern SC and Engelmann WH. The National Human Activity Pattern Survey (NHAPS): a resource for assessing exposure to environmental pollutants. J Expo Anal Env Epid. 2001;11:231-252. 
2. Chao CYH, Wan MP, Cheng ECK. Penetration coefficient and deposition rate as a function of particle size in non-smoking naturally ventilated residences. Atmos Environ. 2003;37:42334241.

3. Lee K, Vallarino J, Dumyahn T, Ozkaynak H. Ozone decay rates in residences. J Air Waste Manage. 1999;49:1238.

4. Mueller FX, Loeb L, Mapes WH. Decomposition rates of ozone in living areas. Environ Sci Technol. 1973;7:342-346.

5. Nazaroff WW, Gadgil AJ, Weschler CJ. Critique of the use of deposition velocity in modeling indoor air quality. Am Soc Test Mater. 1993;1205:81-104.

6. Weschler CJ, Shields H, Shah BM. Understanding and reducing the indoor concentration of submicron particles at a commercial building in Southern California. J Air Waste Manage. 1996;46:291-299.

7. Wang H Morrison GC. Ozone-initiated secondary emission rates of aldehydes from indoor surfaces in four homes. Environ Sci Technol. 2006;40:5263-5268.

8. Weschler CJ, Nazaroff WW. Semivolatile organic compounds in indoor environments. Atmos Environ. 2008;42:9018-9040.

9. Wu Y, Eichler CMA, Leng W, Cox SS, Marr LC, Little JC. Adsorption of phthalates on impervious indoor surfaces. Environ Sci Technol. 2017;51:2907-2913.

10. Sleiman M, Gundel LA, Pankow JF, Jacob P, Singer BC, Destaillats H. Formation of carcinogens indoors by surface-mediated reactions of nicotine with nitrous acid, leading to potential thirdhand smoke hazards. P Natl Acad Sci USA. 2010;107:6576.

11. Hodgson AT, Ming KY, Singer BC, Quantifying object and material surface areas in residences. Lawrence Berkeley National Laboratory; 2005 
12. Seinfeld JH, Pandis SN. Atmospheric Chemistry and Physics: From Air Pollution to Climate Change. Hoboken, N.J.: J Wiley; 2006.

13. Jones PJ, Whittle GE. Computational fluid dynamics for building air flow predictioncurrent status and capabilities. Build Environ. 1992;27:321-338.

14. Abdullahi KL, Delgado-Saborit JM, Harrison RM. Emissions and indoor concentrations of particulate matter and its specific chemical components from cooking: A review. Atmos Environ. 2013;71:260-294.

15. Logue JM, Klepeis NE, Lobscheid AB, Singer BC. Pollutant exposures from natural gas cooking burners: a simulation-based assessment for Southern California. Environ Health Persp. 2014;122:43-50.

16. Seltenrich N. Take care in the kitchen: avoiding cooking-related pollutants. Environ Health Persp. 2014;122:A154-A159.

17. Bruno RC. Verifying a model of radon decay product behavior indoors. Health Phys. 1983;45:471-480.

18. Febo A, Perrino C. Prediction and experimental evidence for high air concentration of nitrous acid in indoor environments. Atmos Environ A-Gen. 1991;25:1055-1061.

19. Reiss R, Ryan PB, Koutrakis P. Modeling ozone deposition onto indoor residential surfaces. Environ Sci Technol. 1994;28:504-513.

20. Thornburg J, Ensor DS, Rodes CE, Lawless PA, Sparks LE, Mosley RB. Penetration of particles into buildings and associated physical factors. Part I: model development and computer simulations. Aerosol Sci Tech. 2001;34:284-296.

21. Sabersky RH, Sinema DA, Shair FH. Concentrations, decay rates, and removal of ozone and their relation to establishing clean indoor air. Environ Sci Technol. 1973;7:347-353. 
22. Fogh CL, Fogh CL, Byrne MA, Roed J, Goddard AJH. Size specific indoor aerosol deposition measurements and derived I/O concentrations ratios. Atmos Environ. 1997;31:21932203.

23. Thatcher TL, Lai ACK, Moreno-Jackson R, Sextro RG, Nazaroff WW. Effects of room furnishings and air speed on particle deposition rates indoors. Atmos Environ. 2002;36:1811-1819. 24. Singer BC, Hodgson AT, Hotchi T, Ming KY, Sextro RG, Wood EE, Brown NJ, Sorption of organic gases in residential rooms. Atmos Environ. 2007;41:3251-3265.

25. Nazaroff WW, Cass GR. Mathematical modeling of chemically reactive pollutants in indoor air. Environ Sci Technol. 1986;20:924-934.

26. Hayes S. Estimating the effect of being indoors on total personal exposure to outdoor air pollution. JAPCA. 1989;39:1453-1461.

27. Abt E, Suh HH, Allen G, Koutrakis P. Characterization of indoor particle sources: A study conducted in the metropolitan Boston area. Environ Health Persp. 2000;108:35-44.

28. Scheff PA, Paulius VK, Curtis L, Conroy LM. Indoor air quality in a middle school, part II: development of emission factors for particulate matter and bioaerosols. Appl Occup Environ Hyg. 2000;15:835-842.

29. Hussein T, Glytsos T, Ondráček J, Dohányosová P, Ždímal V, Hämeri K, Lazaridis M, Smolík J, Kulmala M. Particle size characterization and emission rates during indoor activities in a house. Atmos Environ. 2006;40:4285-4307.

30. Gehan EA, George SL. Estimation of human body surface area from height and weight. Cancer Chemoth Rep 1. 1970;54:225-235. 


\section{Chapter 3. Conclusions}

\subsection{Conclusions}

Conceptual and numerical models are important tools for understanding the transport, transformation, and fate of gases and particles indoors. Among the inputs to such models are the surface area and volume of the indoor setting, often combined as the surface-area-to-volume ratio. To properly account for all the contents of a room, we manually measured the surface area, including and excluding contents, of five bedrooms, four kitchens, and three offices, in buildings in Virginia. The overall mean ratio of surface area with contents to that without, $S * / S$, was $1.7 \pm$ 0.2 (mean \pm standard error), meaning that the contents of a room contributed another $70 \%$ to the total surface area beyond that of the walls, floor, and ceiling. The average ratio of volume of freely moving air to volume of the entire room, $V^{*} / V$, was $0.89 \pm 0.05$, meaning that the contents occupied only about $11 \%$ of space in a room. The ratio of surface area without contents to volume, $S / V$, was $1.9 \pm 0.3 \mathrm{~m}^{-1}$, and $S^{*} / V^{*}$ was $3.7 \pm 1.2 \mathrm{~m}^{-1}$, nearly two times higher compared to the ratio that ignores contents. All calculated metrics in this study were not significantly different by type of room.

Kitchens had the largest variability amongst any room type, as kitchens 2 and 4 were significantly larger than kitchens 1 and 3 in volume. Generally, the amount of miscellaneous contents beyond major furnishings and appliances dictated $S * / V^{*}$, and messier rooms had a higher $S * / V^{*}$. While these measurements contribute new information about surface area indoors, they underestimate the true surface area that is accessible to gases and particles, as we necessarily used a resolution of $\sim 1 \mathrm{~cm}$ when measuring objects. The largest 9-20 contents, including ceiling, floor, and each individual wall, in a room accounted for $90 \%$ of its total surface area. 
We also characterized the shape and material of objects in the rooms. The majority of objects were flat surfaces, dominated by walls, floor, ceiling, cabinets, closet doors, and windows. Paint was typically the most common surface type, largely due to walls and ceilings. This information can be used to improve models of the fate and transport of gases and particles in indoor environments.

\subsection{Recommendations for Future Work}

The results from this study can be used to improve the understanding of the behavior of gases and particles in indoor environments, as well as support the development of improved models of contaminant transport indoors. The calculated surface-area-to-volume ratios can be used for developing realistic model simulations of air flow indoors, updating previously published models, or improving predictions of deposition and re-emission rates.

We measured the surface-area-to-volume ratio, including and excluding contents, of a small sample of three types of rooms: bedrooms, kitchens, and offices. The same methods could be applied to different indoor environments such as child care centers, classrooms, open offices, shopping malls, vehicle cabins, and other places where people spend a great deal of time. A laborsaving approach might be to use image processing or Light Detection and Ranging (LIDAR) to measure surface area, although these would require considerable method development. 